\title{
Weldability of S700MC steel welded with the hybrid plasma + MAG method
}

\author{
Beata Skowrońska ${ }^{1}$, Tomasz Chmielewski ${ }^{1}$, Dariusz Golański ${ }^{1, *}$, and Jacek Szulc ${ }^{2}$ \\ ${ }^{1}$ Warsaw University of Technology, Institute of Manufacturing Technologies, 85 Narbutta Str., 02-524 Warsaw, Poland \\ 2 SUPRA ELCO, 3 Gimnazjalna Str., 01-364 Warsaw, Poland
}

Received: 22 November 2019 / Accepted: 3 January 2020

\begin{abstract}
The paper describes the microstructure of welded joints produced by the plasma + MAG (Metal Active Gas) method of S700MC high yield strength steel (700 MPa). Welded joints of thermomechanical steel have been made with different values of heat input. The results of metallographic research of welded joints, microstructure of the weld and heat affected zone, hardness distribution and impact toughness are presented. The heat affected zone consists of two sub-zones with different grain size and lowered hardness. The tensile test show that strength of welded joints was slightly reduced and the bending test revealed no crack formation in the weld. The impact toughness of measured welded samples with V-notch in HAZ (heat affected zone) reached high values that are higher comparing to samples with notch placed in the weld area. The investigation results show that the use of plasma concentrated heat source together with MAG welding arc does not significantly change the structure and deteriorate properties of welded S700MC thermomechanically treated high strength steel. The hybrid plasma + MAG welding method has a potential to become a beneficial alternative to other welding processes due to its high efficiency, reduced amount of weld metal content or limited requirements for a preparation of edges of welded joints.
\end{abstract}

Keywords: Plasma + MAG / hybrid welding / high strength steel / S700MC

\section{Introduction}

Continuous development of welding processes has led to the emergence of new varieties hybrid welding usually combining two welding methods: arc welding with concentrated energy beam welding, e.g. laser. In this type of welding process, the temperature field is created by the simultaneous interaction of an electric arc and, e.g., a concentrated laser beam. An example of hybrid welding is most often a combination of the laser welding method with the MAG (Metal Active Gas) method [1] or the TIG (Tungsten Inert Gas) method [2]. Other hybrid welding variants are based on the combination of concentrated plasma arc and MAG (plasma + MAG) [3]. Plasma + GMA (Gas Metal Arc welding) hybrid welding combines the advantages of both solutions used in this method. On the one hand, the heat source in the form of high-energy plasma ensures deep penetration, and the classic GMA heat source fills up the welding groove. Such a combination significantly increases the welding efficiency, reduces the weld metal content, and

\footnotetext{
* e-mail: dgol@wip.pw.edu.pl
}

most importantly, reduces the need for precise preparation of the edges for the welding process, which in industrial conditions often becomes impossible. Plasma hybrid welding is from an investment and operational point of view a much cheaper solution compared to the one in which the laser is used. This innovative plasma + GMA welding method is based on the use of a special magnetic curtain, thanks to which the current of both the plasma arc and the arc from GMA flows through the welded material. Otherwise, it would endure each other due to opposite polarization [4].

The described method combines the MAG (Metal Active Gas) arc welding process and the plasma welding method to increase the welding performance. The purpose of the plasma application is to achieve deep penetration (opened evaporation canal - keyhole) in welded material. The creation of an evaporation channel is possible when the plasma arc's density is above $10^{10} \mathrm{~W} / \mathrm{m}^{2}$ [5]. The role of the MAG method is to fill the opened channel with the weld metal and create the suitable shape of the face of a weld. The hybrid welding process uses many advantages of both welding heat sources. The hybrid welds can have deep penetration level, comparable with depths obtained by plasma key-hole welding, but at the same time having a 


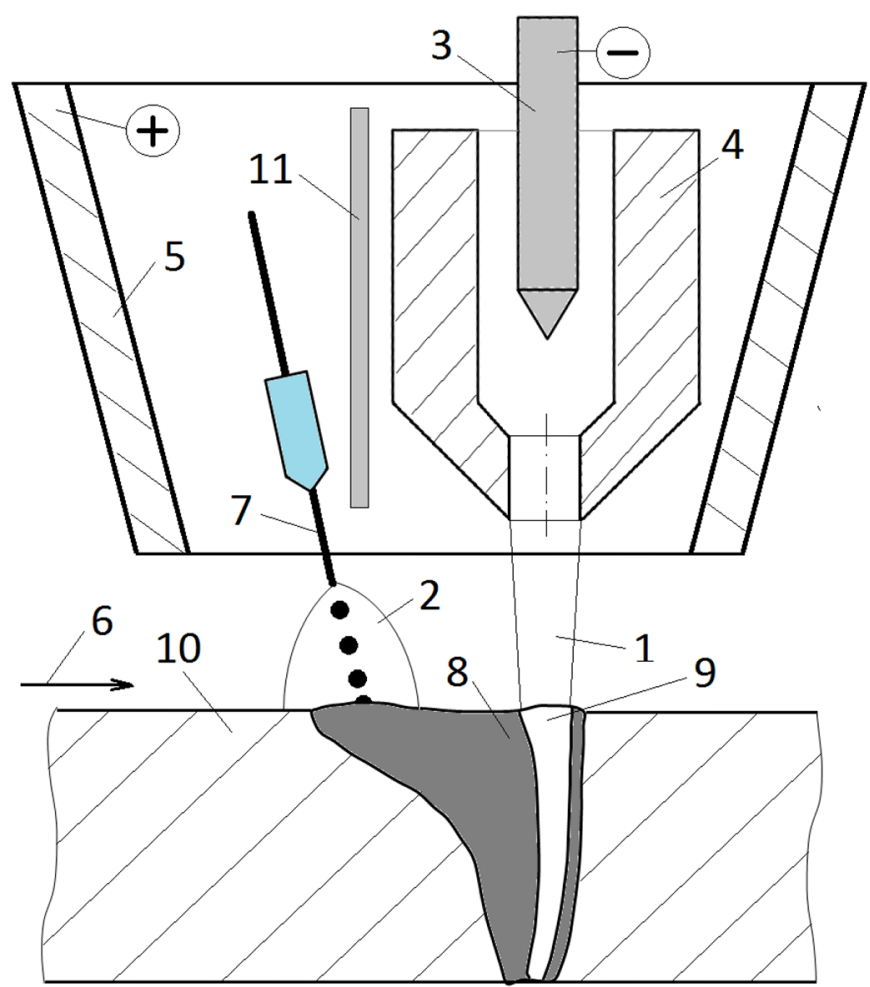

Fig. 1. Schematic drawing of the hybrid plasmatron: 1-plasma arc, 2-MAG arc, 3-plasmatron cathode, 4-plasma nozzle, 5-common shielding gas nozzle, 6-welding direction, 7-MAG wire electrode, 8-liquid metal, 9-plasma keyhole, 10-welded material, 11-magnetic curtain.

tolerance of joints fit-up and weld cap profile more comparable with MAG welds. In general, the hybrid welding system is characterized by an extremely high welding efficiency, measured by the mass of fused metal. It has approximately up to 20 times higher welding efficiency compared to conventional welding methods. It can be assumed that one bead welded by the hybrid plasma + MAG method corresponds to 5 beads produced by the classic welding method. A similar relation exists in relation to welding speed, which achieves much higher values for the hybrid method. Schematic drawing of the hybrid plasmatron is presented in Figure 1. The construction of the hybrid system and its technological properties can be found in literature [6].

The S700MC steel is an attractive construction material with quite simple mechanical composition. It belongs to a group of high strength steels (HSS) which are subjected to thermomechanical treatment in the production process that provides it with high strength properties. On the other hand, it is also sensitive to heat and reacts to it through excessive recrystallization, which weakens the heat affected zone (HAZ). For such materials, the use of hybrid welding methods based on plasma or laser beam should be adequate to reduce the amount of heat introduced into the joint and thus limit the unfavourable changes that may occur in HAZ, due to too much heat introduced.

\section{Hybrid plasma + MAG welding process}

The weldability of S700MC HSS steel is generally good. The biggest problem when welding S700MC steel is the presence of high-temperature coarse grains in the heat affected zone (HAZ).

A rapid decrease of impact toughness in this region is observed due to the nucleation effect of the dissolved phases, strengthening the matrix and their subsequent uncontrolled separation and precipitation in the form of finely dispersion phases. The plasma + MAG hybrid welding tests that have been taken here have shown that in order to ensure high quality of welded joints it is necessary to limit the welding linear energy input. During the welding process of S700MC steel, it is not recommended to use both preheating and post welding heat treatment operations. Also, the number of welding repairs should be kept to a minimum, because it leads to a reduction of strength and plastic properties in the HAZ zone as a result of aging processes, dissolution of strengthening phases in the matrix and their subsequent uncontrolled precipitation during cooling [7-13].

The S700MC steel has low carbon coefficient $\left(C_{e}\right)$ and generally is characterized by good weldability therefore it does not need preheating $[7,8]$. If preheating is required it results from the selection of a filler wire and its weldability or limiting the hydrogen content in the weld. In such case the preheating should be kept below $100{ }^{\circ} \mathrm{C}[8,9]$. The welding of S700MC steel by conventional welding methods (e.g. MAG) even with low linear welding energy shows that the application of post weld annealing resulted in a sudden drop of joint's impact toughness below $27 \mathrm{~J} / \mathrm{cm}^{2}[8]$.

Due to high strength properties of S700MC steel it is necessary to try to limit the amount of heat introduced into the material in the welding process, which will have a destructive effect on the properties obtained in the thermomechanical process of steel production. Recrystallization processes developed in HAZ will lead to softening of the material and loss of the initially high strength properties of steel. Also, the welding thermal cycle promotes the solution of fine-dispersive carbides, $\mathrm{Nb}, \mathrm{Ti}$ and $\mathrm{V}$ and their uncontrolled precipitation again $[8,9]$. This may affect the phase transformation in HAZ during cooling and also during post-weld heat treatment which will lead to reduction of impact toughness [9,10]. Introduction a large amount of heat into the welded S700 steel extends the time of holding the HAZ at elevated temperature and lowers its cooling time, which makes the austenite grains to grow and formation of structures that have limited plasticity [10-12]. Hence, both preheating and heat treatment after welding will further promote recrystallization in HAZ and reduce the original mechanical properties.

To study the properties and weldability of S700MC steel welded by the plasma + MAG hybrid system, samples of $10 \mathrm{~mm}$ thick steel S700MC sheets were prepared for butt joints. The sheets were welded in the flat position on a water-cooled copper backing strip using solid filler wire G69 6 M21 Mn4Ni1 with a diameter of $1.2 \mathrm{~mm}$. The preparation of the weld groove is shown in Figure 2. 
Table 1. Chemical composition and mechanical properties of S700MC steel.

\begin{tabular}{|c|c|c|c|c|c|c|c|c|c|c|c|}
\hline \multicolumn{12}{|c|}{ Chemical composition, wt. $\%$} \\
\hline $\mathrm{C}$ & $\mathrm{Si}$ & $\mathrm{Mn}$ & $\mathrm{P}$ & $\mathrm{S}$ & $\mathrm{Al}$ & $\mathrm{Nb}$ & $\mathrm{V}$ & $\mathrm{Ti}$ & $\mathrm{B}$ & Mo & C equivalent \\
\hline 0.059 & 0.253 & 1.912 & 0.009 & 0.006 & 0.027 & 0.057 & 0.021 & 0.087 & 0.087 & 0.106 & 0.33 \\
\hline \multicolumn{12}{|c|}{ Mechanical properties } \\
\hline $\begin{array}{l}\text { Tensile strength } \\
\text { Rm (MPa) }\end{array}$ & & & $\begin{array}{l}\text { Yield stress } \\
\text { Re (MPa) }\end{array}$ & $\begin{array}{l}\text { Elongation } \\
\text { A5 }(\%)\end{array}$ & & & $\begin{array}{l}\text { Hardness } \\
\text { HV }\end{array}$ & & $\begin{array}{l}\text { Impact strength } \\
\mathrm{J} / \mathrm{cm}^{2}\left(-20^{\circ} \mathrm{C}\right)\end{array}$ & & \\
\hline$\overline{830}$ & & & 767 & 19 & & & 280 & & 135 & & \\
\hline
\end{tabular}

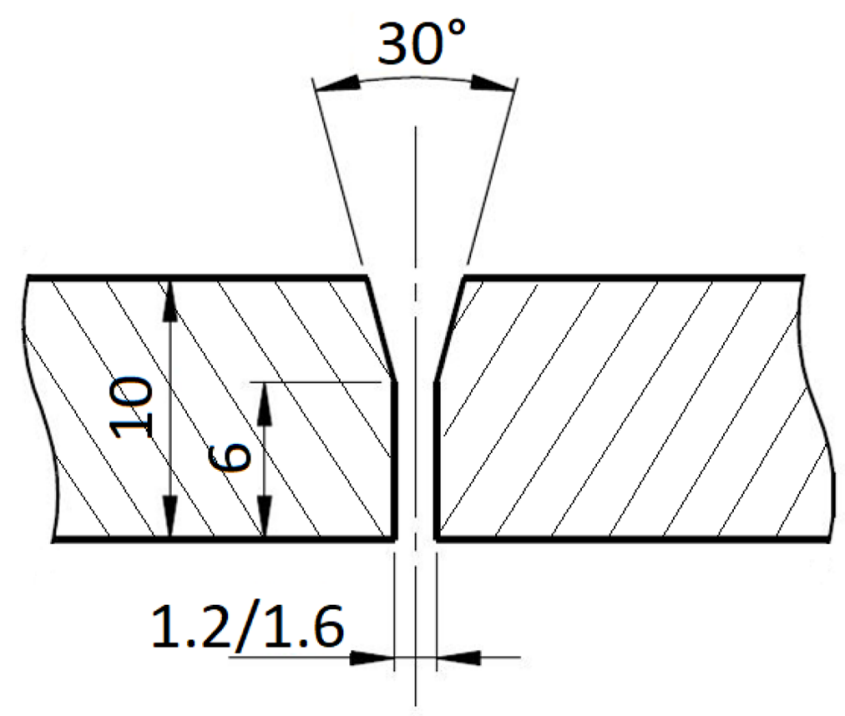

Fig. 2. Geometry of the groove preparation of S700MC sheets for hybrid plasma + MAG welding.

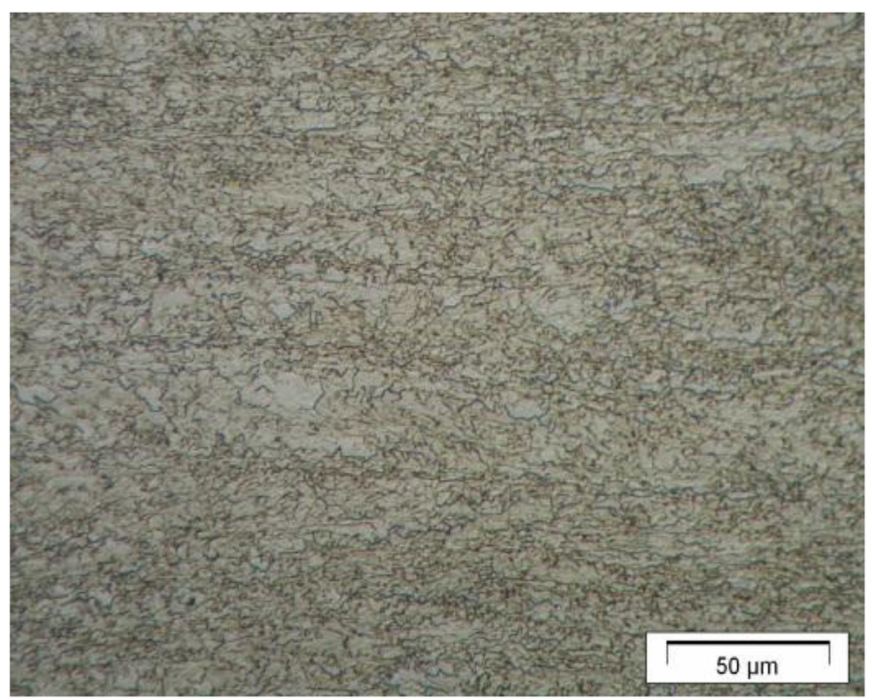

Fig. 3. Microstructure of S700MC steel used in hybrid plasma + MAG welding.
Table 2. Chemical composition of G 696 M21 Mn4Ni1 filler wire.

\begin{tabular}{lllllll}
\hline \multicolumn{7}{c}{ Chemical composition, wt. \% } \\
\hline $\mathrm{C}$ & $\mathrm{Si}$ & $\mathrm{Mn}$ & $\mathrm{Cr}$ & $\mathrm{Ni}$ & $\mathrm{Mo}$ & $\mathrm{Ti}$ \\
\hline 0.09 & 0.55 & 1.67 & 0.25 & 1.52 & 0.50 & 0.07 \\
\hline
\end{tabular}

The edges of the sheets were bevelled to form a $30^{\circ}$ angle groove leaving $6 \mathrm{~mm}$ root face thickness.

The chemical composition and the mechanical properties of the S700MC steel used are shown in Table 1. These data were taken from the manufacturer's (SSAB) certificate of supplied Domex 700MC E steel. The microstructure of S700MC steel is presented in Figure 3. The material has a bainitic-ferritic structure with a visible effect of plastic deformation resulting from the thermomechanical treatment process.

For the hybrid welding a filler wire G 696 M21 Mn4Ni1 (ED-FK 800) with $1.2 \mathrm{~mm}$ diameter was used. This material is dedicated to welding of high strength low alloy steel. It was selected for hybrid welding of S700MC steel due to its high yield stress (above $690 \mathrm{MPa}$ ) which is comparable with the base material. The chemical composition of the filler wire metal is collected from the manufacturer's (Fliess) data sheet and is presented in Table 2.

The hybrid plasma + MAG welding was performed using PLT Hybrid Super-MIG system. The welding plasmatron was mounted in a wrist of industrial KUKA KR 16-2f robot (Fig. 4).

The hybrid welding parameters are presented in Table 3. The plasma gas used in test was $\mathrm{Ar}-100 \%$ and the shielding gas used in the test was mixture $(18 \%$ $\mathrm{CO}_{2}+82 \% \mathrm{Ar}$ ), whereas the gas flow rate amounted to $22 \mathrm{dm}^{3} / \mathrm{min}$. The welding process was carried out using one pass. The parameters used during making the butt joints and other welding conditions (adjusted on the basis of preliminary test) are presented in Table 3. Also, other welded samples with different parameters and heat input level were tested but due to the rather narrow welding parameters window only $\mathrm{C} 2$ and $\mathrm{C} 4$ show no welding imperfections. The other welding samples that were tested did not meet expected mechanical and metallurgical 
Table 3. Parameters of the hybrid butt welding of $10 \mathrm{~mm}$ thickness steel S700MC.

\begin{tabular}{lllllll}
\hline $\begin{array}{l}\text { Sample welded } \\
\text { joint }\end{array}$ & $\begin{array}{l}\text { Plasma arc } \\
\text { voltage, V }\end{array}$ & $\begin{array}{l}\text { Plasma arc } \\
\text { current, V }\end{array}$ & $\begin{array}{l}\text { MAG arc } \\
\text { voltage, V }\end{array}$ & $\begin{array}{l}\text { MAG arc } \\
\text { current, V }\end{array}$ & $\begin{array}{l}\text { Travel speed } \\
\mathrm{m} / \mathrm{min} .\end{array}$ & $\begin{array}{l}\text { Heat input, } \\
\mathrm{kJ} / \mathrm{mm}\end{array}$ \\
\hline $\mathrm{A}$ & 23.4 & 335.4 & 31.8 & 360.6 & 0.75 & 1.11 \\
$\mathrm{~B}$ & 23.9 & 332.4 & 33.6 & 390.7 & 0.95 & 0.96 \\
\hline
\end{tabular}

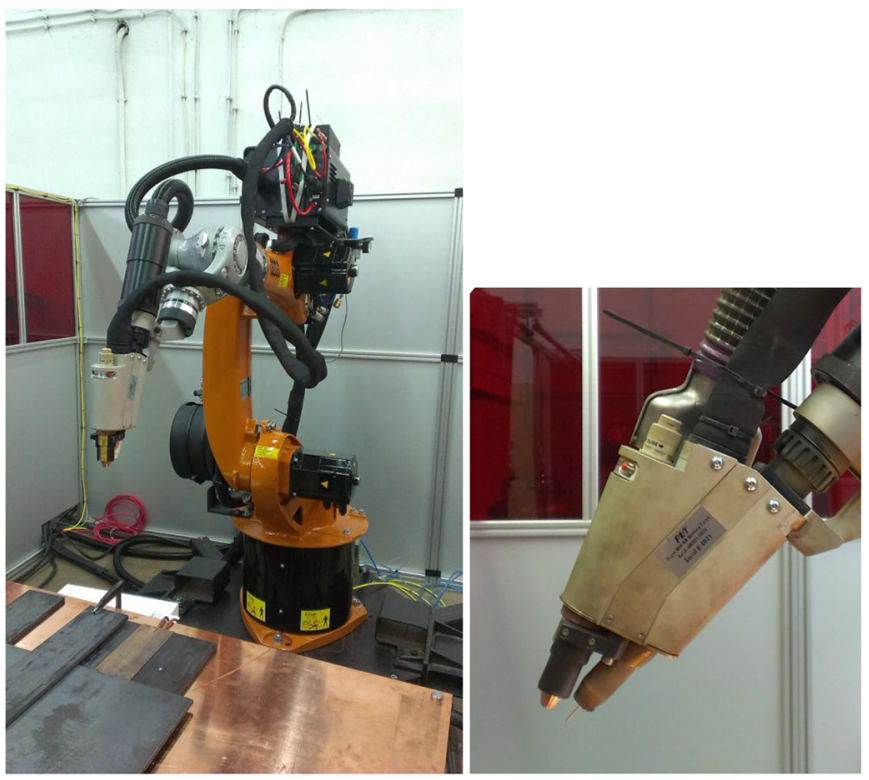

Fig. 4. Kuka KR16-2f welding robot with hybrid plasma + MAG Super-MIG torch system mounted.

properties but also an important criterion that disqualified the remaining samples was improper geometrical parameters of the weld, such as incorrect shape of the weld face. The welded samples $\mathrm{C} 2$ and $\mathrm{C} 4$ that were chosen for the further investigations were renamed as sample A (higher heat input) and sample B, respectively (lower heat input).

\section{Investigation results}

\subsection{Microstructure observation}

Hybrid welded joints were prepared for testing by cleaning the surface in accordance with the procedure described in the literature $[14,15]$. Welded joints were tested by visual examination and by the magnetic particle test which did not reveal shape and surface welding imperfections. The welded joints satisfied the requirements related to quality level B according to ISO 12932. The microscopic observations did not show the presence of welding imperfections both in weld and in the heat affected zone (Fig. 5). The shape and dimension of weld root reflected the shape and dimensions of the copper backing strip used during welding. We may distinguish double HAZ in the joint. This probably results from the fact that in the hybrid welding process we have almost simultaneous interaction of two arcs (plasma and classical arc) with significantly different heat concentration densities. The heating mechanism is different in both heat sources (the plasma arc creates a 'keyhole' gas channel, while the classic arc creates a liquid weld pool and the heat is transferred based on conduction). Both arches interact to some extent (overlap) and with significantly different amount of heat introduced into the material, a characteristic HAZ is created containing two different sub-zones.

The microscopic observations revealed a bainiticferritic microstructure in the weld area. The structure of the base material is characterized by a banded grain arrangement with visible plastic deformation resulting from the production process of S700MC grade steel which is based on controlled rolling with accelerated cooling. This effect, due to the high temperature of the welding process, was lost in HAZ2 (fine-grained structure), while in HAZ1, in the high-temperature area, significant grain growth occurred.

The HAZ was characterised by variable-sized grains, which resulted from a significant heat input during the welding process (Fig. 6a-d). The microscopic observation showed the probability of nitride precipitates present in the HAZ and in the base material. Because the hybrid Plasma + MAG welding is characterized by a relatively short cooling time from 800 to $500{ }^{\circ} \mathrm{C}$ temperature, the HAZ contains the martensite. However, as it is a lowcarbon martensite, it has no strong negative effect on plastic properties of welded joints. In a specific region of the heat affected zone with an increase of the distance from the fusion line, the ferrite content seems to be increasing instead of bainite [16-21].

During microscopic examinations, precipitations ranging from a few to several $\mu \mathrm{m}$ were also observed (Fig. 6c). According to literature [7], if the precipitates have sharp shapes, then they are $\mathrm{Ti}$ carbonitrides, and the precipitations with a black point in the middle, probably crystallized on steel impurities (they do not block grain boundaries).

The smallest precipitation occurring in welds was also very rarely observed. They were much more numerous in the areas of HAZ1 and HAZ2. The presence of carbonitrides in this zone indicates their high thermal stability. The presence of such discontinuities can affect the reduction of strength and plastic properties of welded joints (they may become a place of initiation of cracks).

More detailed investigation was performed using EDS microanalysis. The analysis results from the weld area show similar element distribution (Fe, C, Mn, Si) in all three tested regions (Fig. 7). Both sample joints A and B revealed very close element distribution in the weld area. 

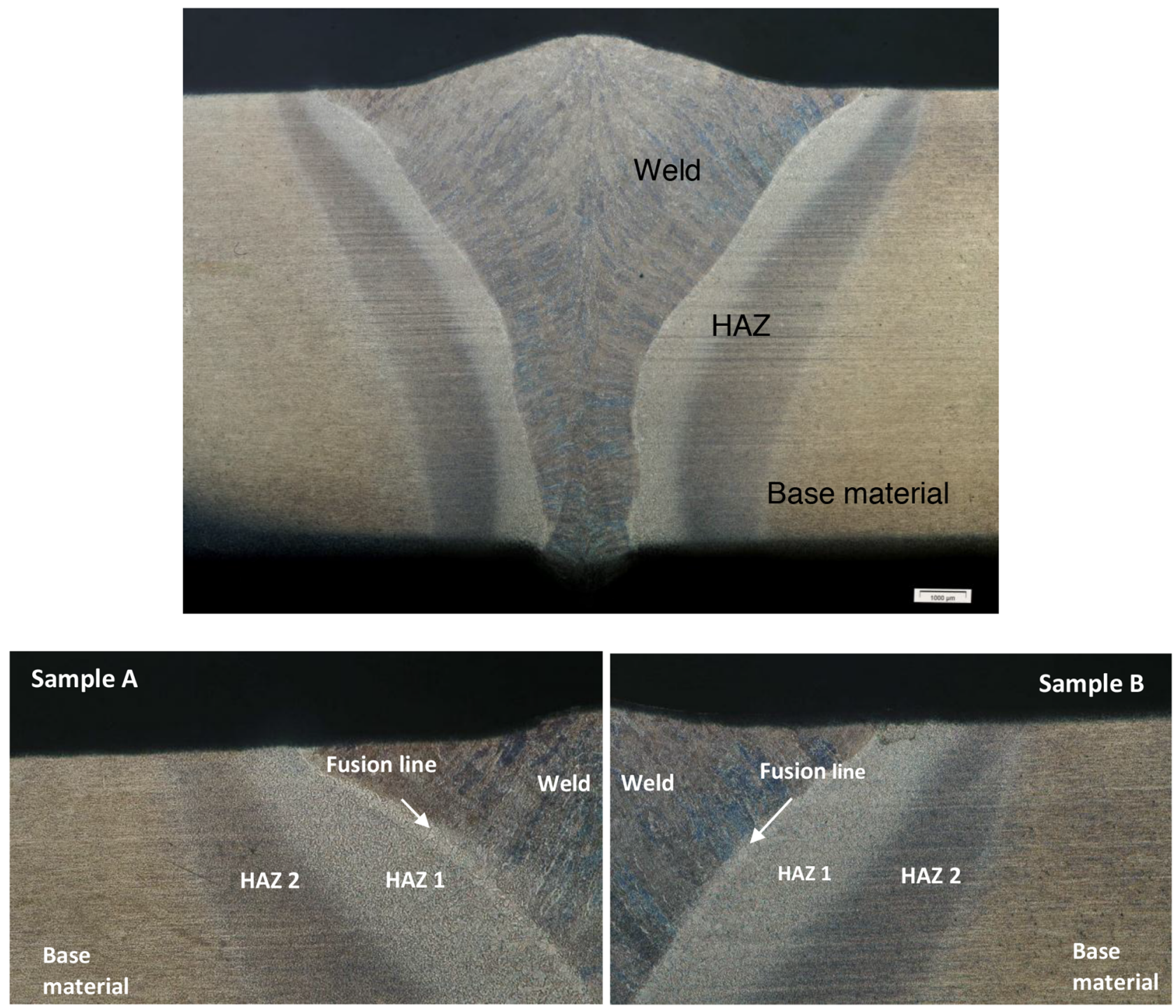

Fig. 5. Microstructure of the hybrid plasma + MAG welded joints made of S700MC steel: sample A and sample B.

Further analysis revealed the presence of titanium and niobium in selected regions. They may contribute to develop other phases in the structure of weld area (Fig. 8).

The results of the EDS analysis in selected part of the HAZ1 are presented in Fig. 9. We may find alloying elements $(\mathrm{Ti}, \mathrm{Nb})$ deriving probably from the base material.

The element distribution in the HAZ2 region adjacent to the base material does not show any special character (Fig. 10). The presence of iron, carbon, manganese and silicon throughout the observed microstructure seems not to drive sudden changes in element distribution on the analyzed section line. Only certain increase of manganese at the precipitated phases can be visible.

The grain size measurement in samples A and B have been performed in three regions - base material, HAZ1 and HAZ2. The mean grain size was estimated according to the EN ISO 643 standard based on micrographic method. A sample A microstructure image of analysed HAZ1 (Fig. 11a) and HAZ2 (Fig. 11b) with software selected grain boundaries and grain visualization by image processing is shown in Figure 11.

The mean values of calculated grain size in both $\mathrm{A}$ and B welded samples are gathered in Table 4. It shows the HAZ1 sub-zone contains large grains with approximate size of $2.21 \mu \mathrm{m}$, very fine grains in HAZ2 sub-zone of approx. $0.28 \mu \mathrm{m}$ (recrystallization effect) and also fine grains in the base material with mean size of $0.55 \mu \mathrm{m}$. These results confirm the degradation of the HAZ1 sub-zone in S700MC steel by the welding thermal cycle resulting in growth of the grain size.

\subsection{Mechanical testing}

Further mechanical tests of the S700MC hybrid welded joints were carried out - tensile strength, bending tests of joints from the face and root side, and impact tests. The 
a)

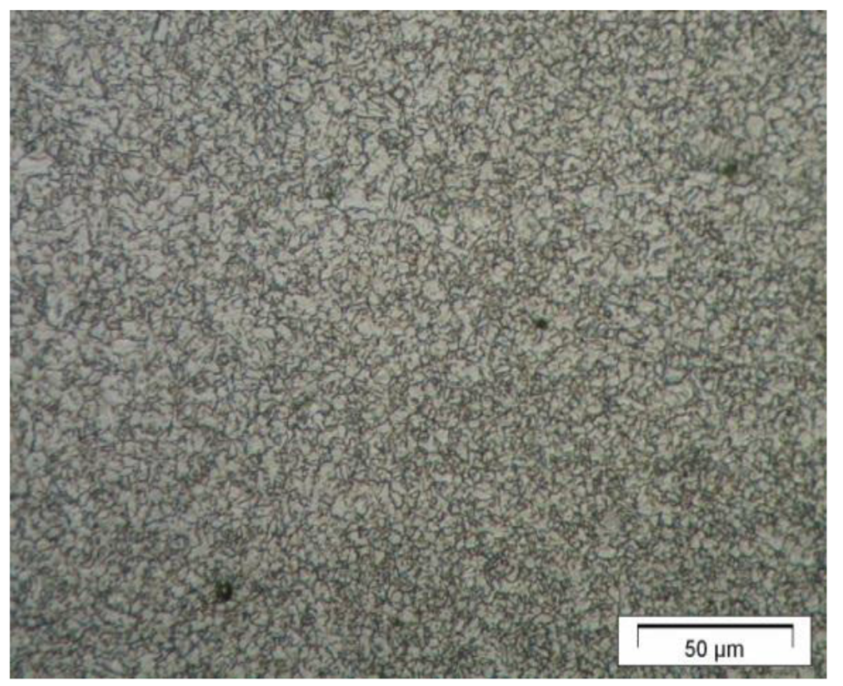

c)

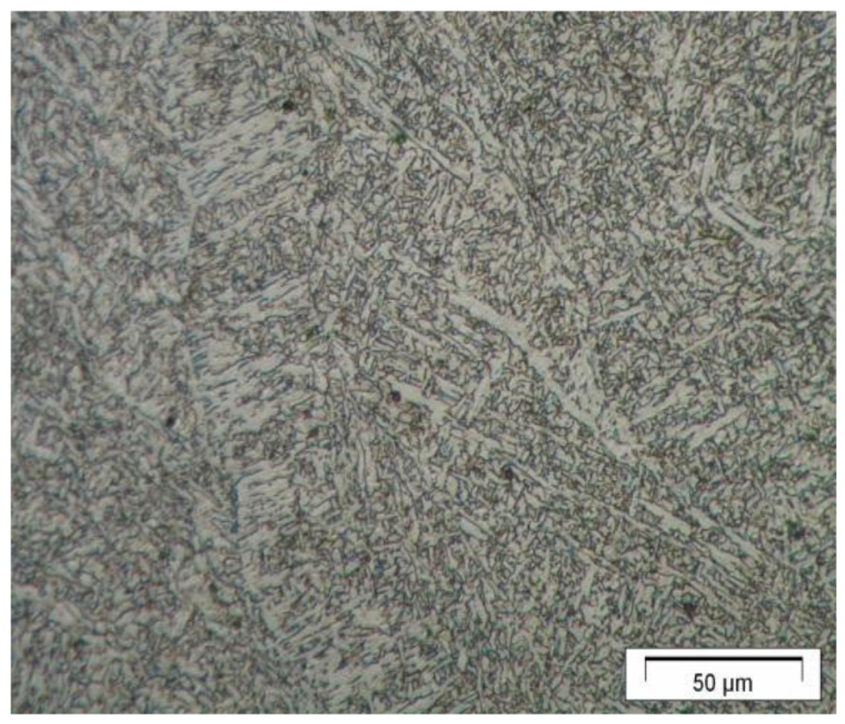

b)

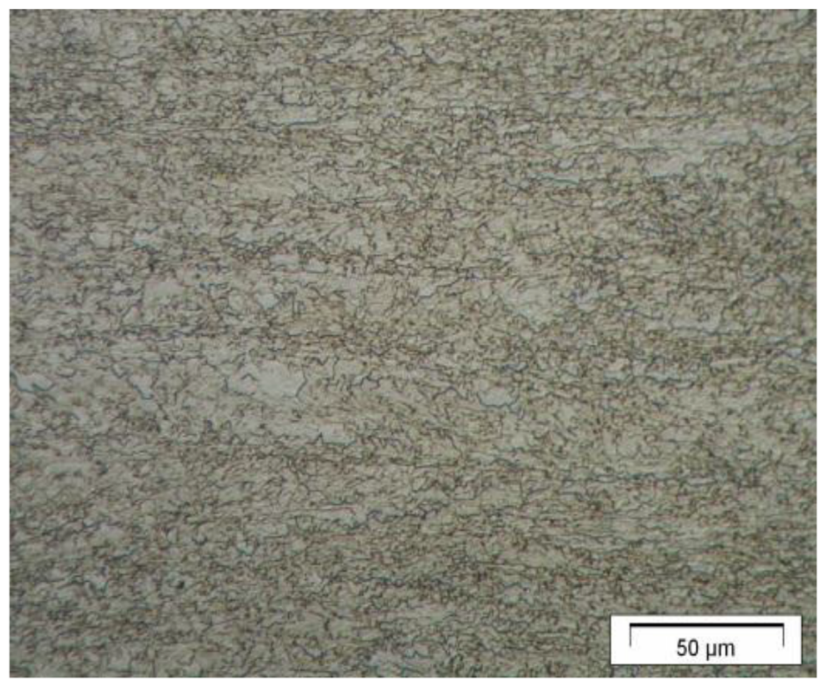

d)

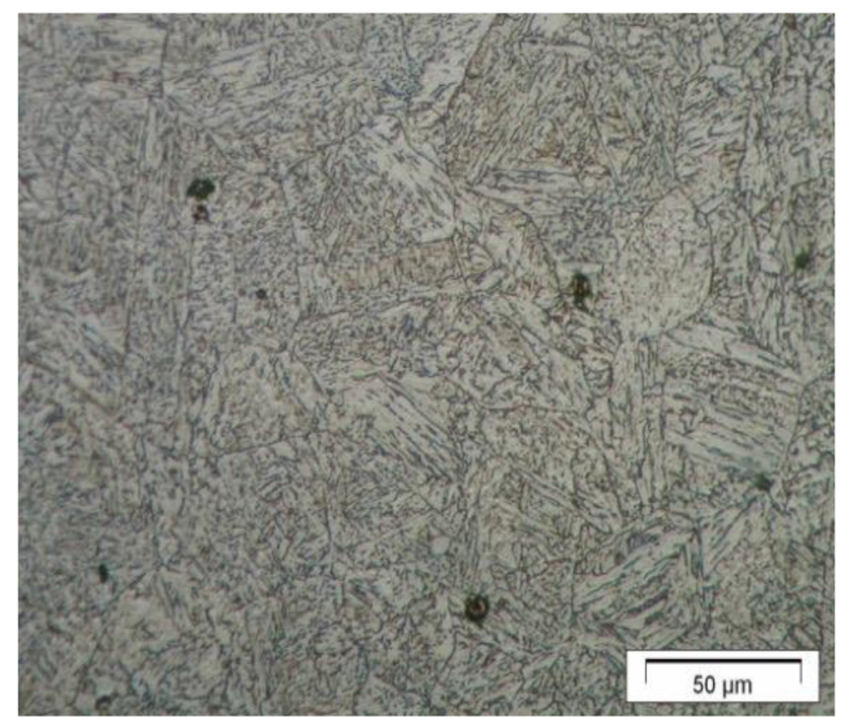

Fig. 6. Microstructure of the hybrid plasma + MAG welded joint (sample A): (a) base material, (b) HAZ2 from the base material side, (c) HAZ1 close to the fusion line, (d) weld material.

Table 4. Results of mean grain size estimation in base material, HAZ2 and in HAZ1 based on EN ISO 643 standard.

\begin{tabular}{llcl}
\hline Sample & Base material & HAZ2 & HAZ1 \\
\hline & & Approximate grain size $(\mu \mathrm{m})$ & \\
$\mathrm{A}$ & $0.55($ mean G number & $0.28($ mean G number $)$ & 2.21 (mean G number \\
& $11.87 \mu \mathrm{m}-$ assumed 12$)$ & $14.25 \mu \mathrm{m}-$ assumed 14$)$ & $7.98 \mu \mathrm{m}-$ assumed 8$)$ \\
B & $0.55($ mean G number & $0.28($ mean G number & $2.21($ mean G number \\
& $11.87 \mu \mathrm{m}-$ assumed 12$)$ & $14.26 \mu \mathrm{m}-$ assumed 14$)$ & $7.99 \mu \mathrm{m}-$ assumed 8$)$ \\
\hline
\end{tabular}


a)

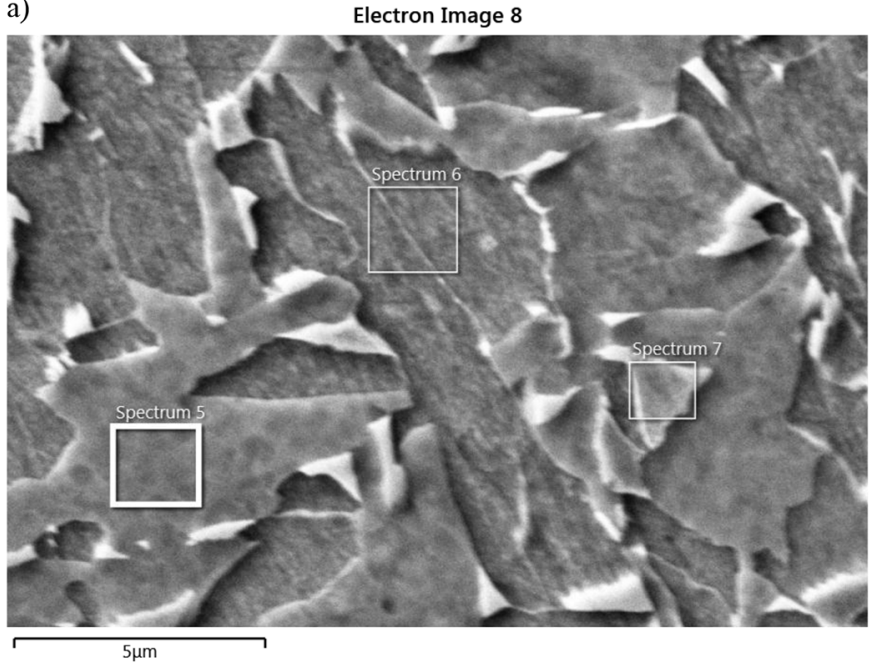

b)

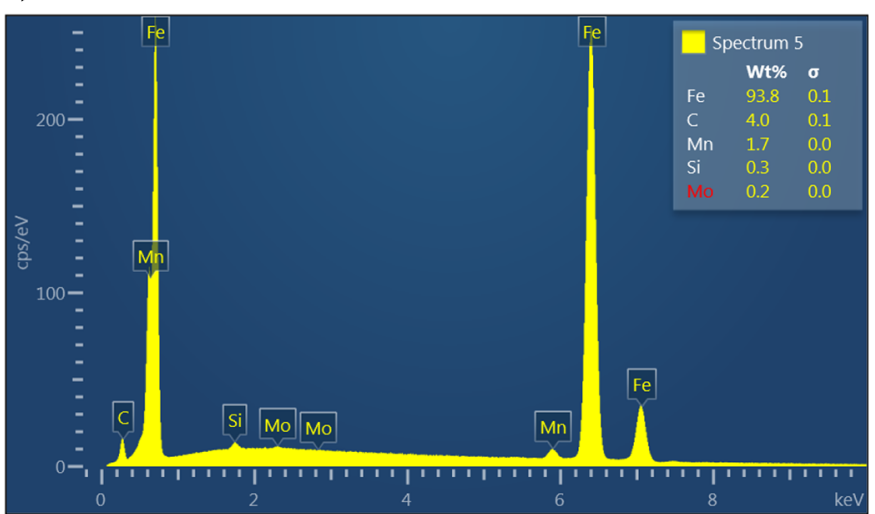

Fig. 7. EDS microanalysis results in the weld area of sample A joint (spectrum 5).

tensile tests were carried out in accordance with requirements of the EN-ISO 15614-14 standard. The sample size and dimensions are presented in Figure 12.

The hybrid plasma + MAG welding process resulted in a slight decrease of tensile strength (approx. $\mathrm{Rm}=770 \mathrm{MPa}$ in all tested samples) from $820 \mathrm{MPa}$ of the base material. The fracture took place in the weld area for all tested samples (Fig. 13).

The amount of base material in the weld is at a level exceeding $50 \%$ - thus, the chemical composition of the weld may have been significantly reduced. The tensile strength of the applied filler metal equals to $770 \mathrm{MPa}$, so improvement of joint's tensile strength can be achieved, e.g. by choosing a different one filler material.

The bending tests were performed according to PN-EN ISO 5173:2010 with geometry of samples shown in Figure 14. The three point bending was performed on the machine with maximal force of $F=50 \mathrm{kN}$. The loading with a pin roll of $15 \mathrm{~mm}$ radius was performed on samples both from the face and root sides. The results show no failure up to the maximum loading force, which demonstrated high plastic properties of the joint.

The Charpy impact test was performed at the temperature of $-30^{\circ} \mathrm{C}$ according to PN-EN 10045-1:1994 on welded samples with v-notch located in the weld and in the HAZ (Fig. 15). The VEB Werkstoffprüfmachinen Leipzig impact testing machine was used with initial impact energy of $300 \mathrm{~J}$.

The obtained results presented satisfactory impact toughness values in the weld, fusion line, and in the HAZ. It is noteworthy that in all tested joints the impact toughness was higher in the samples with notch located in HAZ in contrast to a notch in weld area. For sample A of welded joint it was $203 \mathrm{~J} / \mathrm{cm}^{2}$ with a notch in $\mathrm{HAZ}$ and $117 \mathrm{~J} / \mathrm{cm}^{2}$ with a notch in weld. In sample B of welded joint it was $169 \mathrm{~J} / \mathrm{cm}^{2}$ with a notch in $\mathrm{HAZ}$ and $99 \mathrm{~J} / \mathrm{cm}^{2}$ with a notch in weld. The higher impact toughness observed for samples with notch located in HAZ is reflected by the fact that they were not completely divided by the impact energy. One of the reasons for such results may be a double heat cycle and two sub-zones developed in HAZ. Basing on the view of fractured surfaces of tested joints we may say that fractured samples with notch located in the HAZ presents mixed mode of fracture described by delamination and ductile type (lower pictures in Fig. 16). On the other hand, the samples with notch in the weld present brittle type of fracture (upper pictures in Fig. 16) and the microstructure of fractured samples is characterized by fine grains. The higher impact toughness is demonstrated by the joint made with higher welding energy (sample A), having a smaller share of parent material in the weld.

The collected results from mechanical testing of hybrid welded joints for samples A and B are presented in Table 5. The mechanical testing was conducted using a series of four samples in each test.

The microhardness measurements were performed across the base, HAZ and the weld area running in two sections at a distance of $2 \mathrm{~mm}$ from the steel sheet surface at the weld face side and $2 \mathrm{~mm}$ from the steel sheet surface at the weld root side. From the microhardness distribution (Figs. 17 and 18) we can see that comparing sample-A and sample-B hardness distributions, both from the face and root side, it showed higher hardness (in each characteristic area of the joints) has a joint produced with a lower linear welding energy (sample-B). A significant decrease in hardness was observed in the heat affected zone both in HAZ1 and HAZ2 sub-areas. In these areas the greatest softening is found in HAZ2. A decrease in the average hardness (compared to the average hardness in the base material) was also noted in the weld: about $25 \mathrm{HV} 0.1$ in A samples, and about $15 \mathrm{HV} 0.1$ in B samples. 
a)
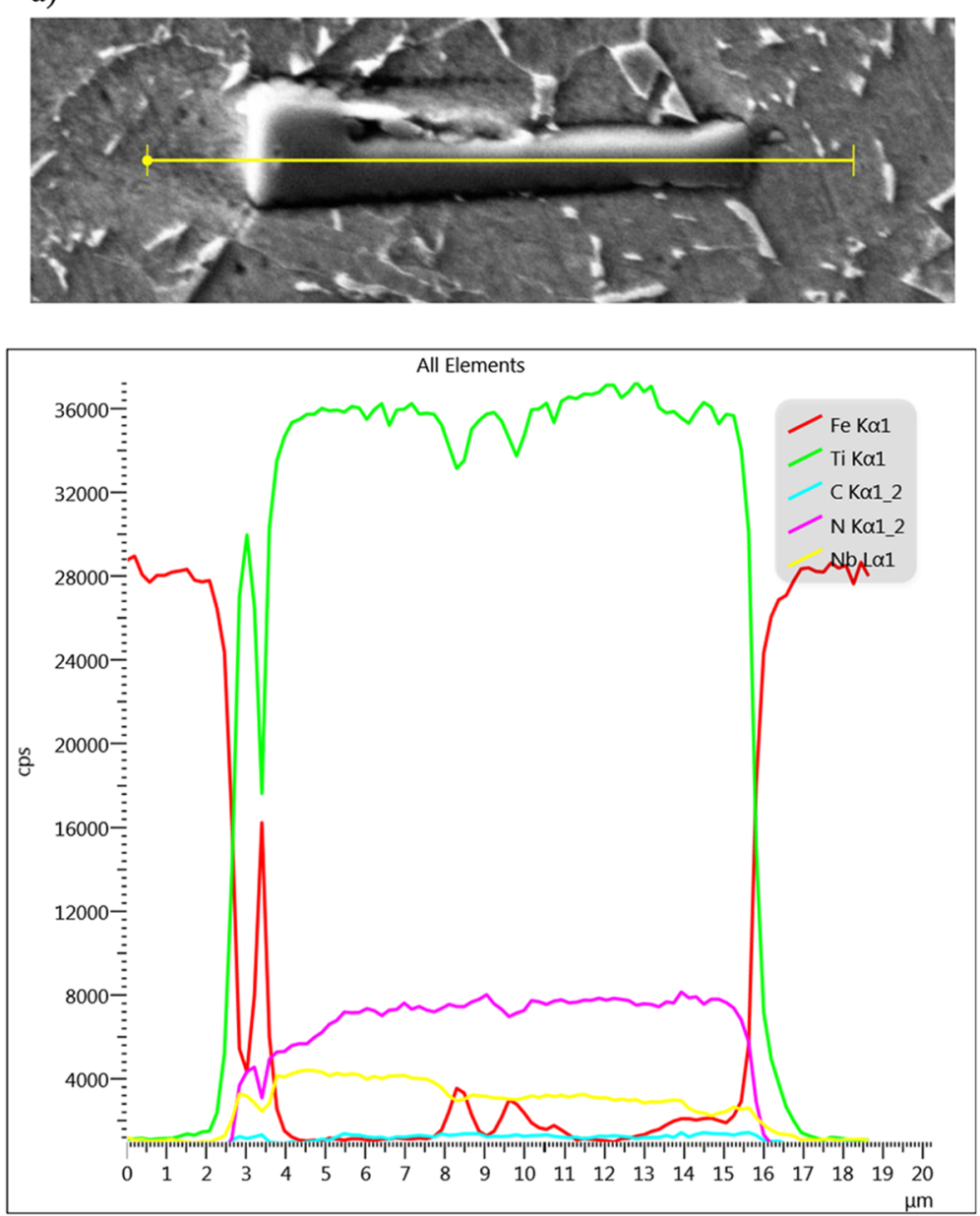

b)

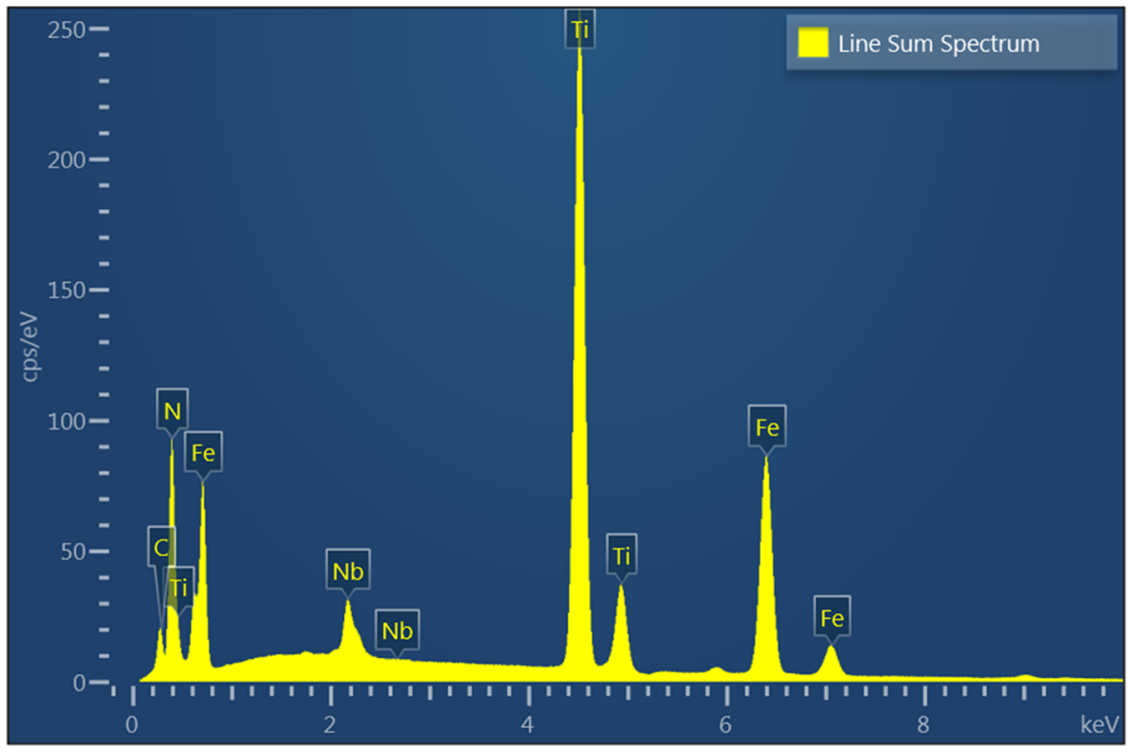

Fig. 8. EDS microanalysis results in the weld area. 
a)

\section{Electron Image 5}

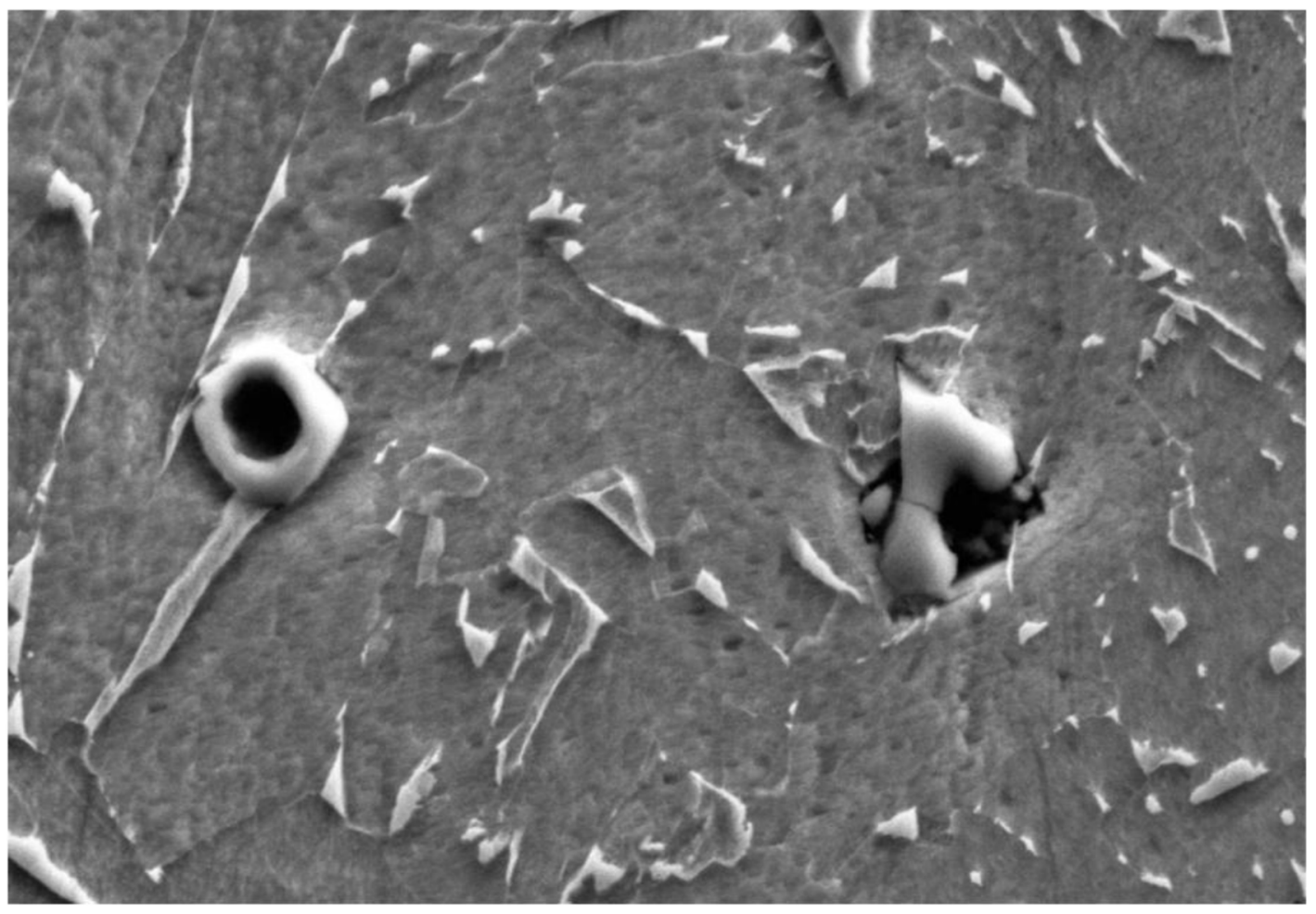

$5 \mu \mathrm{m}$

b)

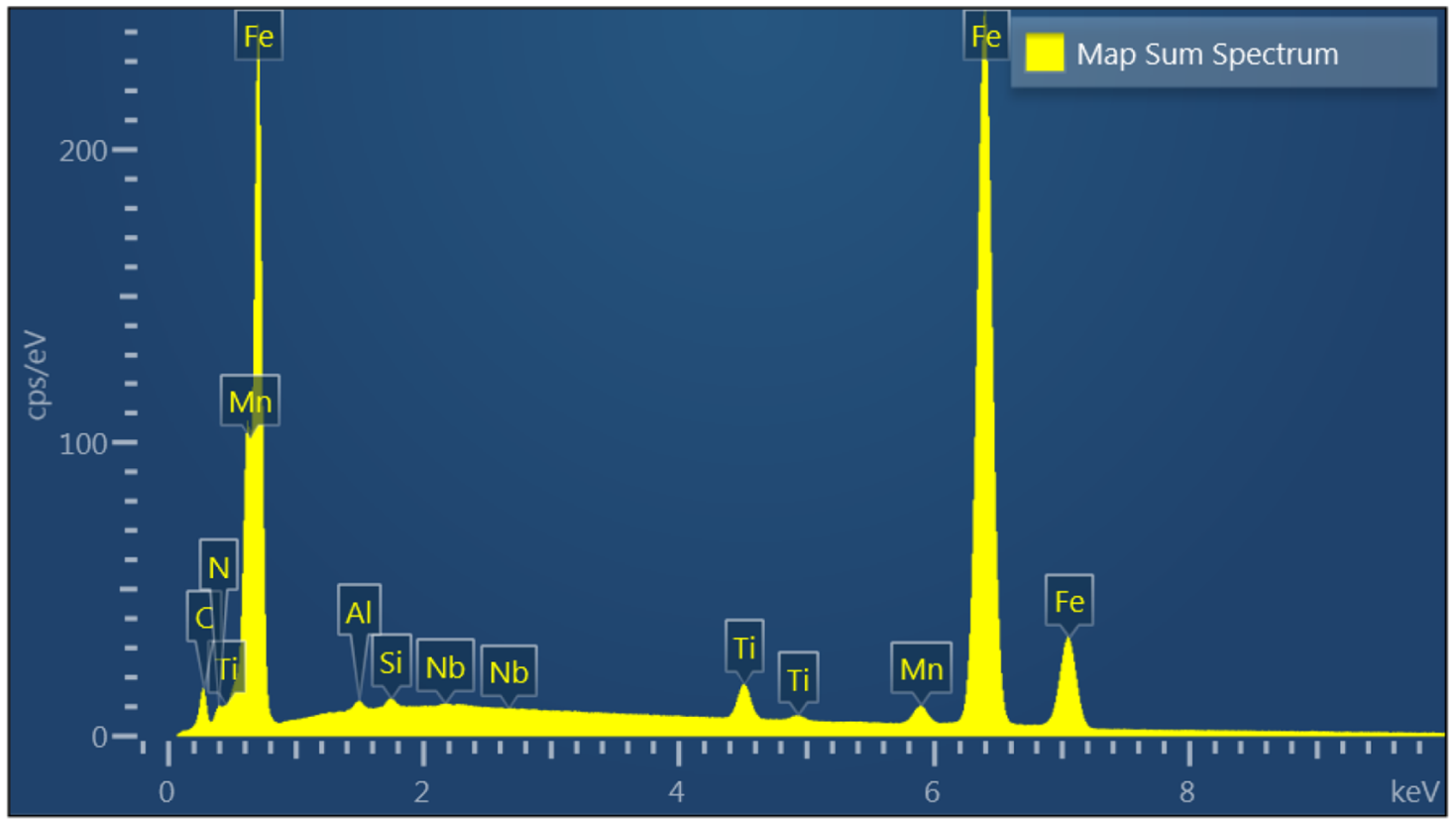

Fig. 9. EDS microanalysis results in the HAZ 1 area (sample A joint). 

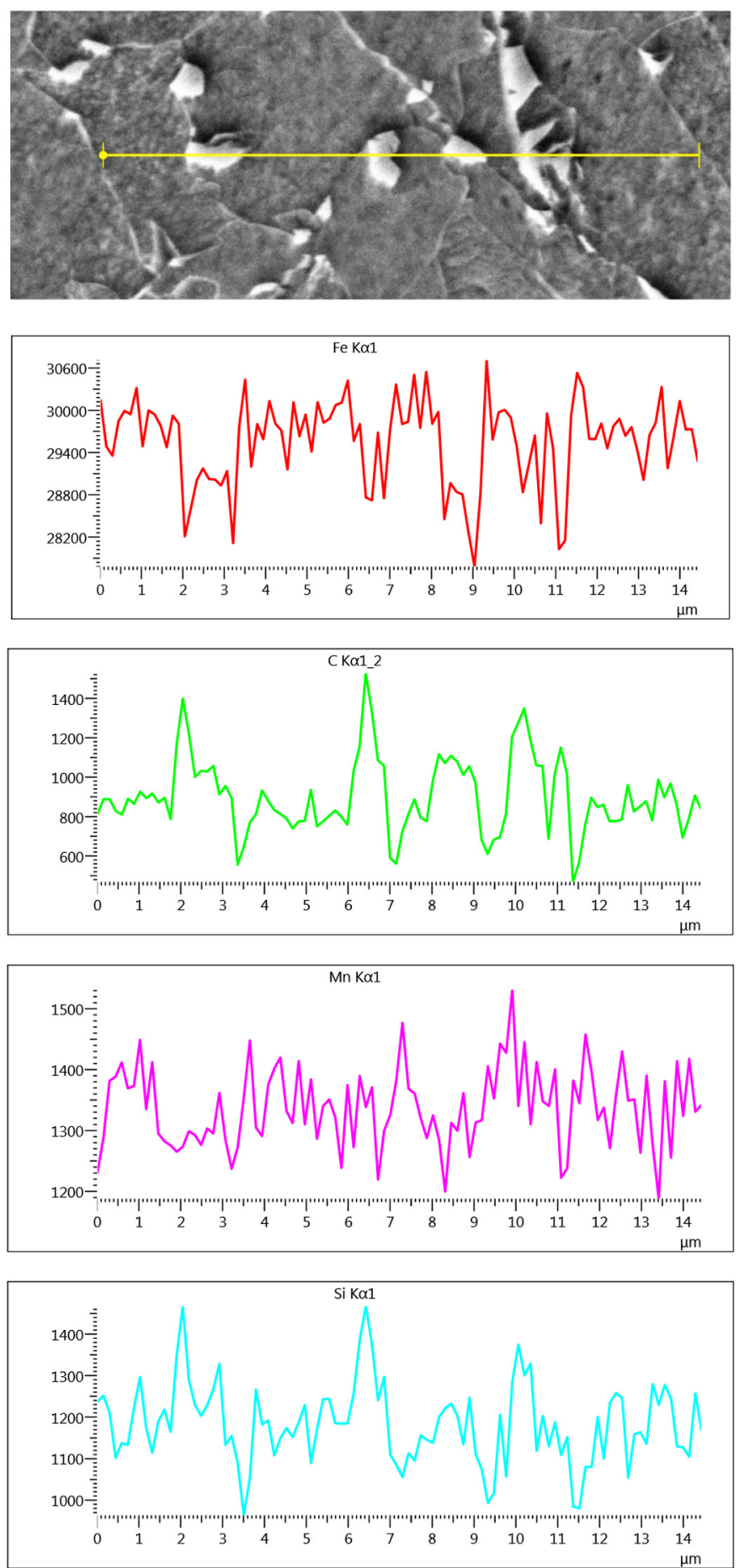

Fig. 10. Linear element distribution registered in HAZ2 of sample A joint.

\section{Conclusions}

The investigations of the hybrid plasma + MAG welding of thermomechanically treated S700MC steel with the use of a filler solid wire showed the possibility of making welded joints $(10 \mathrm{~mm}$ thick) that can satisfy the criteria formulated in the ISO 15614-14 standard. The tested joints were characterised by the absence of welding defects with respect to the shape, geometry, and discontinuity. The microscopic observation of the hybrid welded joints revealed that the welds have the typical bainitic-ferritic microstructure of dendritic nature. The heat affected zone consisted of two sub-zones of variously sized grains, which was the effect of the welding thermal cycle. 
a)

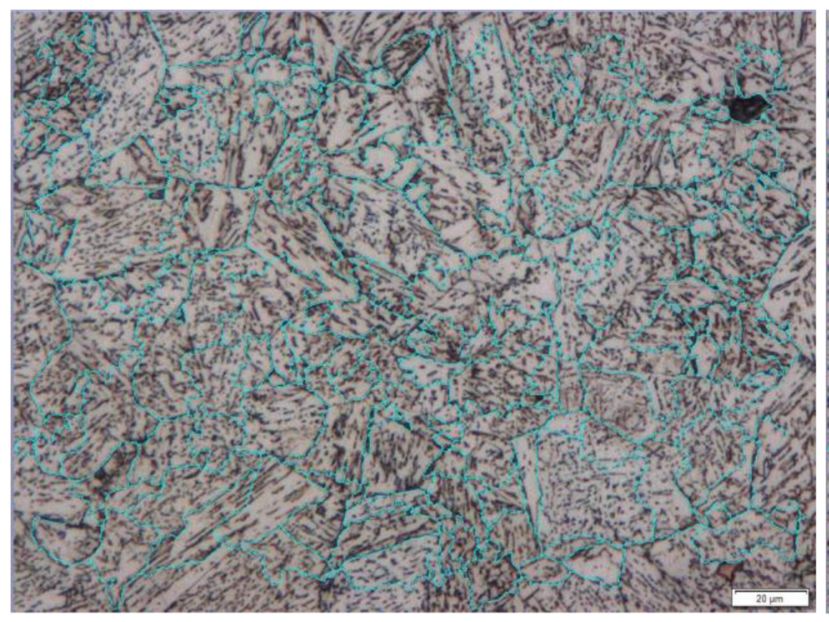

c)

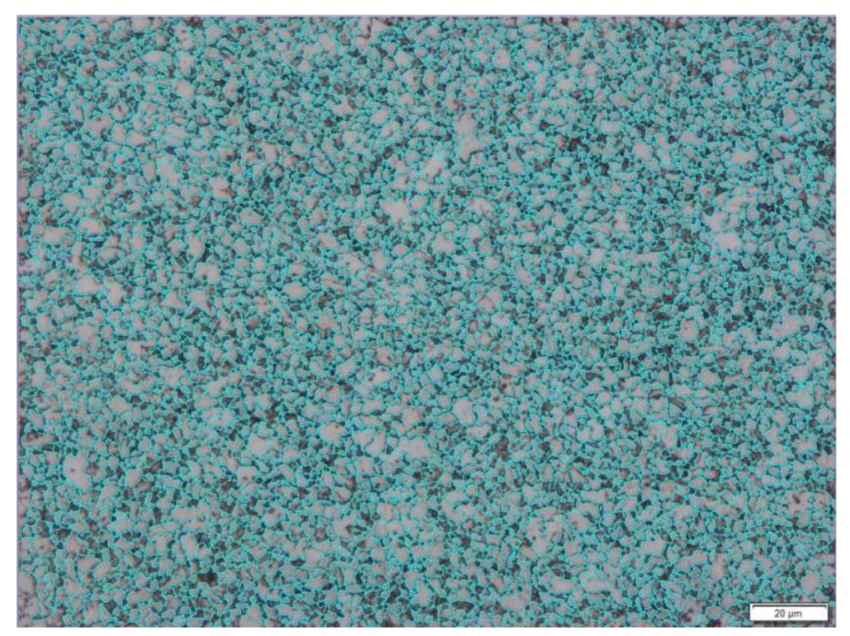

b)

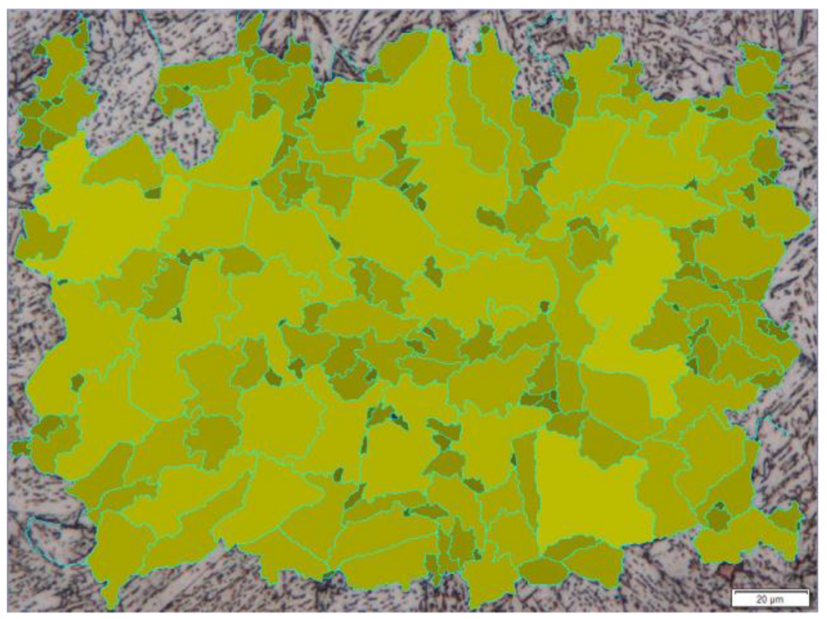

d)

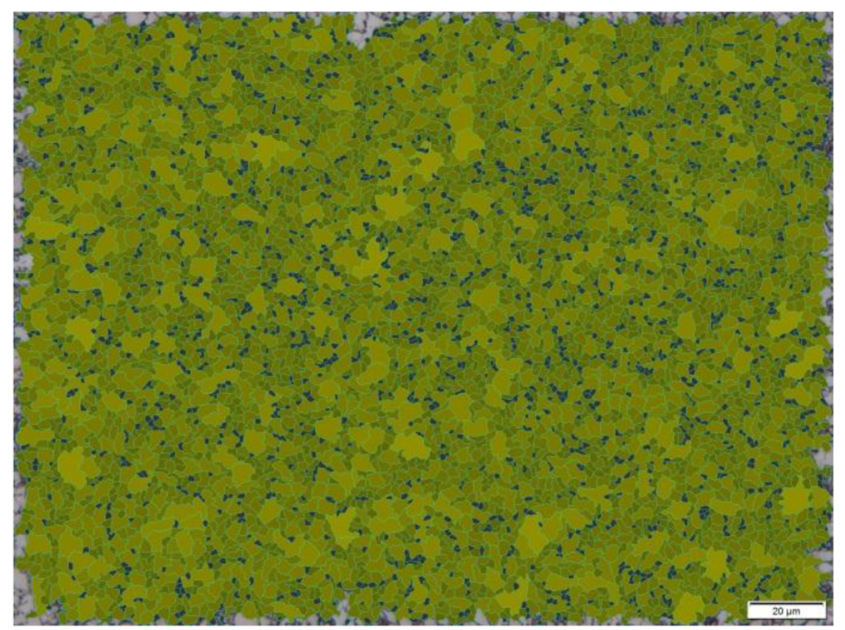

Fig. 11. Images of microstructure in sample B and their corresponding grain size representation by micrographic analysis method performed in HAZ1 (a) and in HAZ2 (b) sub-zones.

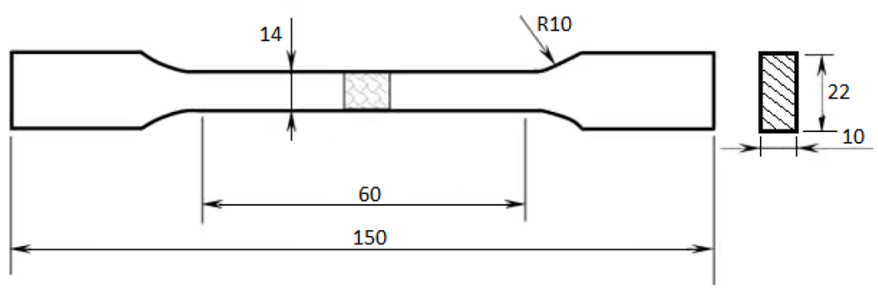

Fig. 12. Geometry of hybrid welded samples used in tensile testing.

The measured tensile strength of the hybrid welded joints was slightly lower to that of the base material, while maintaining satisfactorily the plastic properties. The hardness distribution showed a certain decrease in the area of the fusion line but in a relatively narrow range which should not affect the performance of the welded joint.
To sum up, the conducted research allows drawing the following conclusions:

- It is possible to make correct weld with the required quality and properties of single-pass welded $(10 \mathrm{~mm})$ joint of S700MC steel with the hybrid plasma + MAG method. 
a)

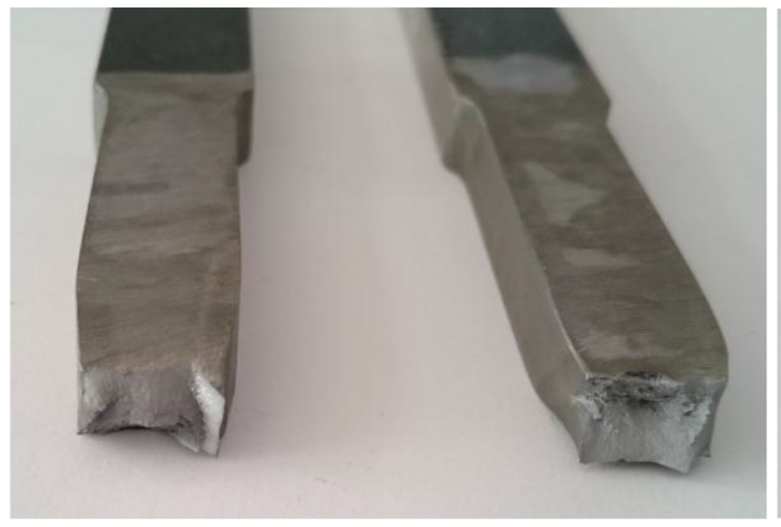

b)

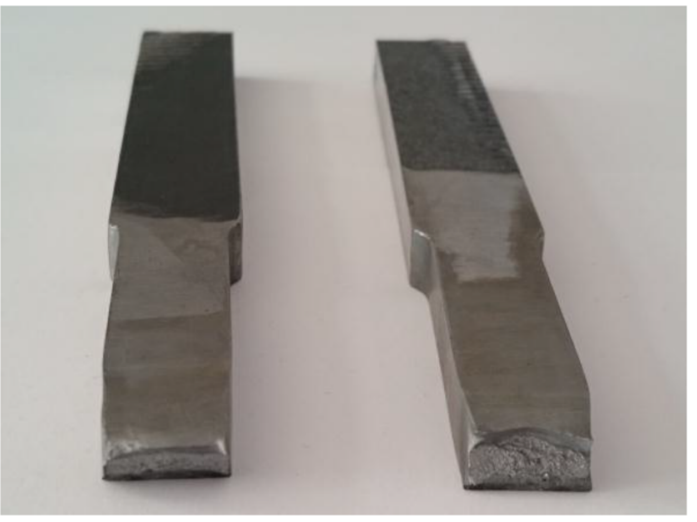

Fig. 13. Damaged samples after tensile testing (a) sample A and (b) sample B.

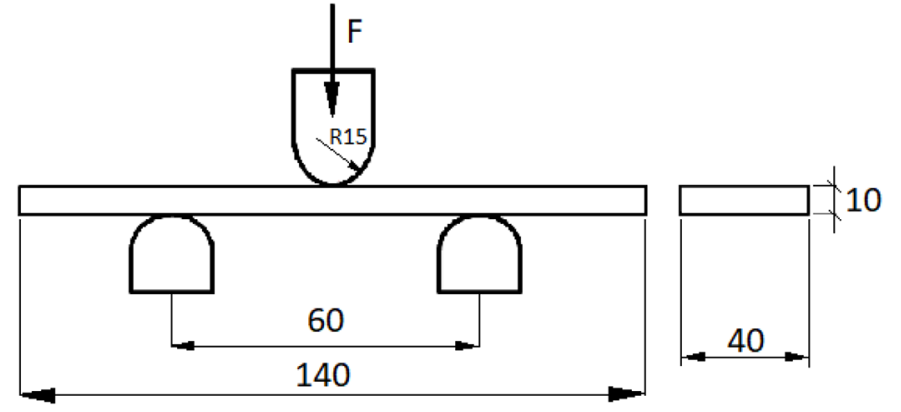

Fig. 14. Configuration of bending test and dimensions of welded samples.

- In the heat-affected zone, two subzones HAZ1 and HAZ2 can be distinguished, differing in microstructure and hardness. In the HAZ1, significant grain growth occurred accompanied by lowered microhardness.

- The decrease in the average hardness in the joint depends on the linear welding energy - the joint made with a lower energy input (sample B) was characterized by a smaller hardness decrease.

- The impact toughness at the temperature of $-30{ }^{\circ} \mathrm{C}$ measured in samples with notch in HAZ reaches very high values. This may be the result of a double heat cycle and a two-zone area formed in HAZ. Higher impact toughness is found in joints made with higher linear welding energy (sample A).

\section{Implications and influences}

The results presented in this manuscript broaden the knowledge about welding of S700MC high strength steel using hybrid plasma + MAG method. The use of steel with high yield strength allows both a reduction in the weight of the structure and the consumption of steel. The application of an innovative hybrid plasma + MAG welding method has a potential to become a beneficial alternative to other welding processes (including hybrid

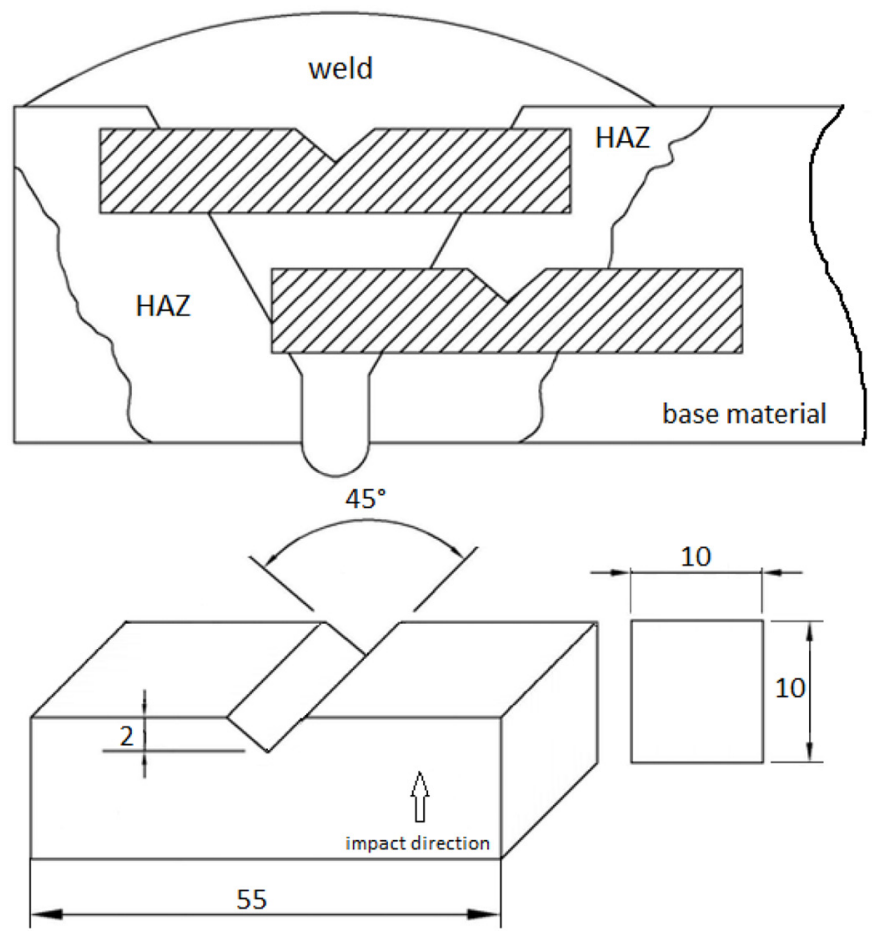

Fig. 15. Charpy test sample size and dimensions, place of cutting out samples from the welded joint.

laser+GMA) due to its high efficiency, reduced the amount of weld metal content or limited requirements for precise preparation of the joint edges. Also, the investigation results show that the use of plasma concentrated heat source together with MAG welding arc does not significantly change the structure and deteriorate properties of welded S700MC thermomechanically treated high strength steel.

The work was financially supported by the Institute of Manufacturing Technologies of the Warsaw University of Technology. 
Table 5. Results of tensile, bending and Charpy impact test carried out on type A and type B samples produced by hybrid plasma + MAG welding.

\begin{tabular}{|c|c|c|c|c|c|}
\hline Mechanical test & Sample & & $\begin{array}{l}\text { Average force } \\
(\mathrm{kN})\end{array}$ & $\begin{array}{l}\text { Standard } \\
\text { deviation }(\mathrm{kN})\end{array}$ & $\begin{array}{l}\text { Average ultimate tensile } \\
\text { strength }(\mathrm{MPa})\end{array}$ \\
\hline \multirow{2}{*}{ Tensile } & A & & 107.6 & 1.14 & 768.7 \\
\hline & $\mathrm{B}$ & & 108.0 & 1.37 & 771.4 \\
\hline \multirow[t]{3}{*}{ Bending } & $\mathrm{A}$ & Bending angle $180^{\circ}$ & & & \\
\hline & $\mathrm{B}$ & Bending angle $180^{\circ}$ & & & \\
\hline & & & $\begin{array}{l}\text { Average impact } \\
\text { energy }(\mathrm{J})\end{array}$ & $\begin{array}{l}\text { Standard } \\
\text { deviation }(\mathrm{J})\end{array}$ & $\begin{array}{l}\text { Average impact toughness at } \\
-30^{\circ} \mathrm{C}\left(\mathrm{J} / \mathrm{cm}^{2}\right)\end{array}$ \\
\hline \multirow{4}{*}{ Impact } & A & Weld & 93 & 15.97 & 117 \\
\hline & & $\mathrm{HAZ}$ & 162 & 28.80 & 203 \\
\hline & B & Weld & 79 & 11.10 & 99 \\
\hline & & HAZ & 135 & 30.59 & 169 \\
\hline
\end{tabular}

a)
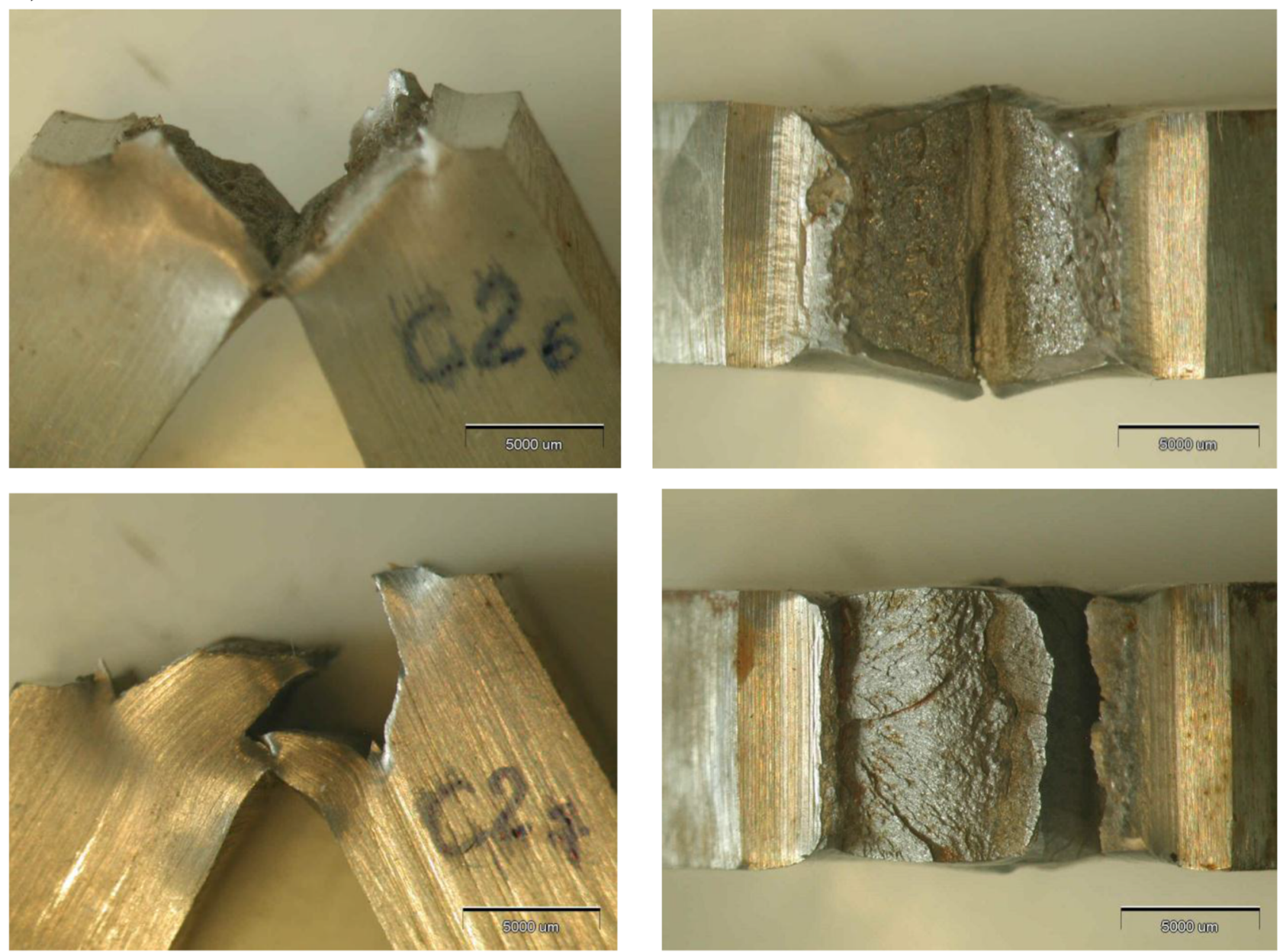

Fig. 16. Fractured area of hybrid plasma $+\mathrm{MAG}$ welded joints: (a) sample A - notch in weld (upper) notch in HAZ (lower), (b) sample B - notch in weld (upper), notch in HAZ (lower). 
b)
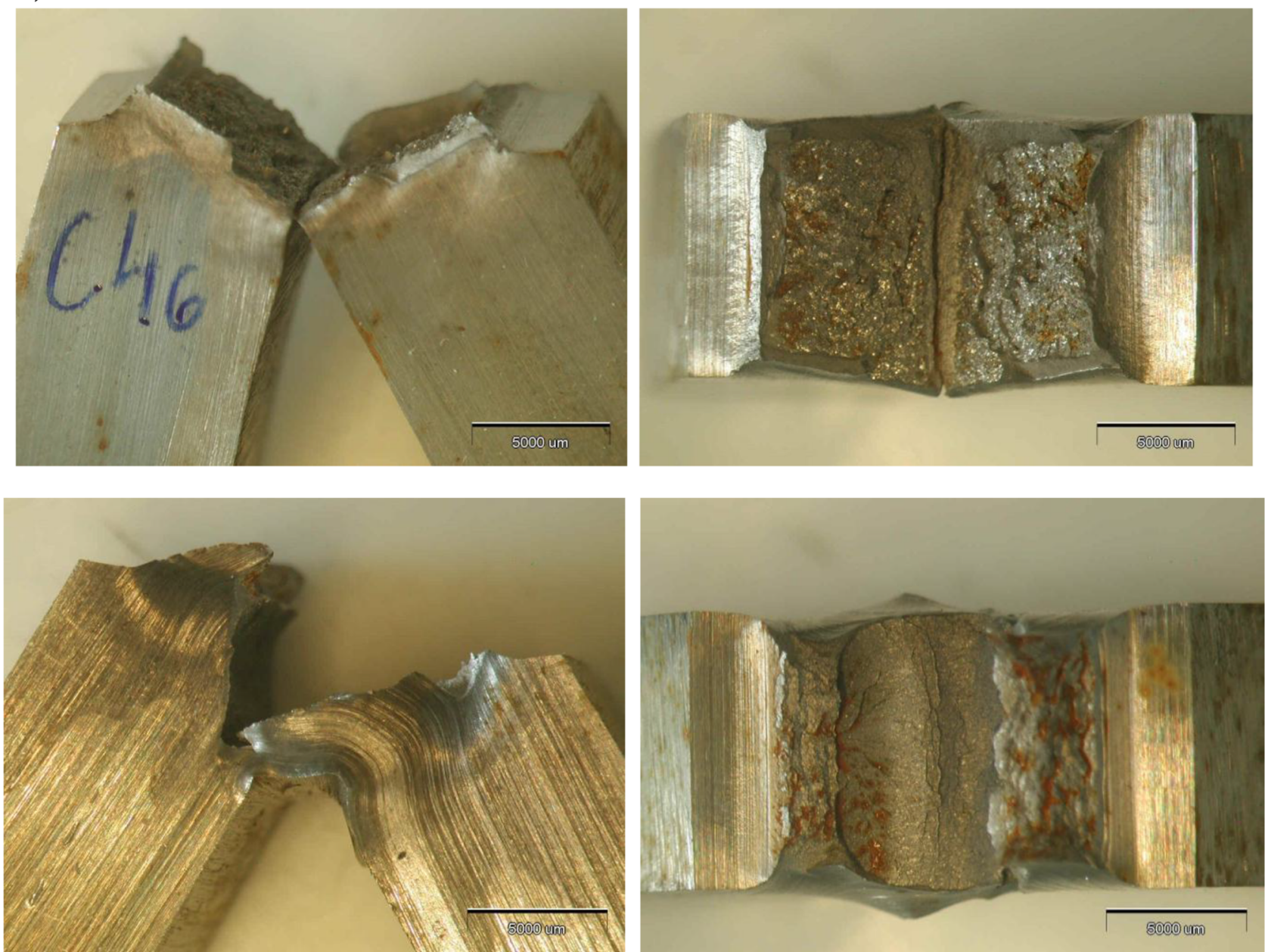

Fig. 16. Continued.

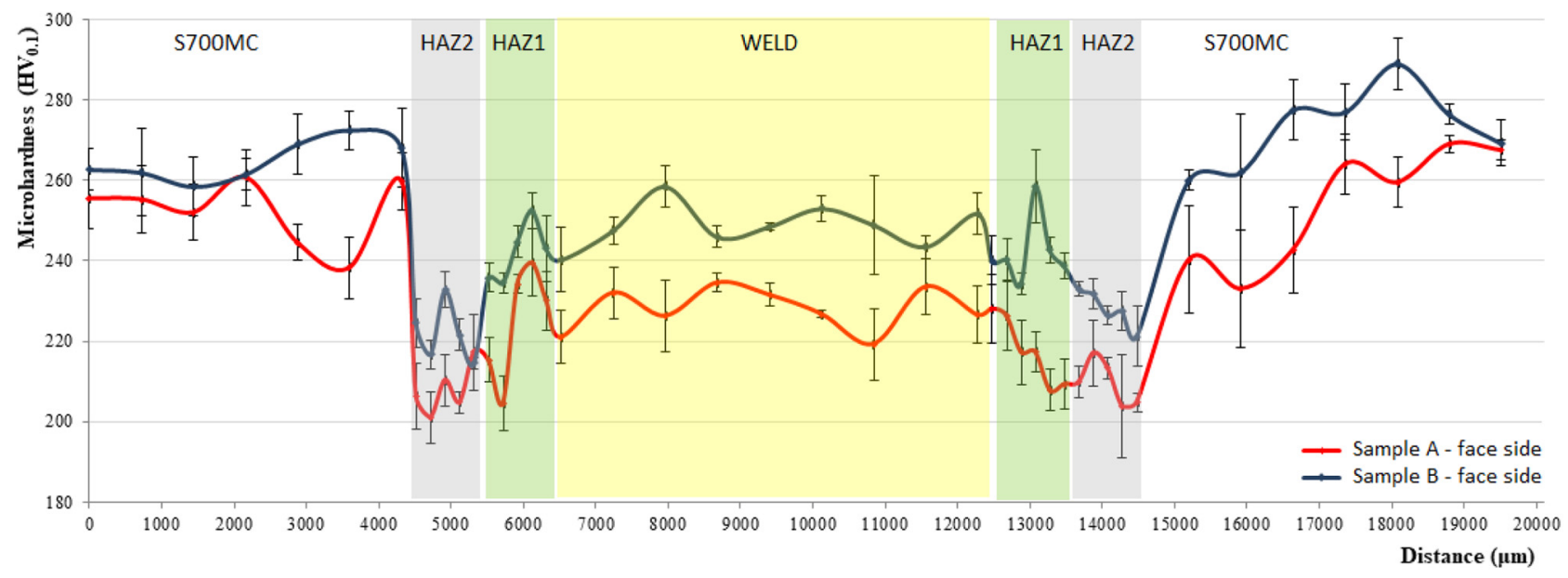

Fig. 17. Microhardness distribution in the hybrid plasma + MAG welded joints made of S700MC steel ( $2 \mathrm{~mm}$ from the top surface of the sheet at the face side). 


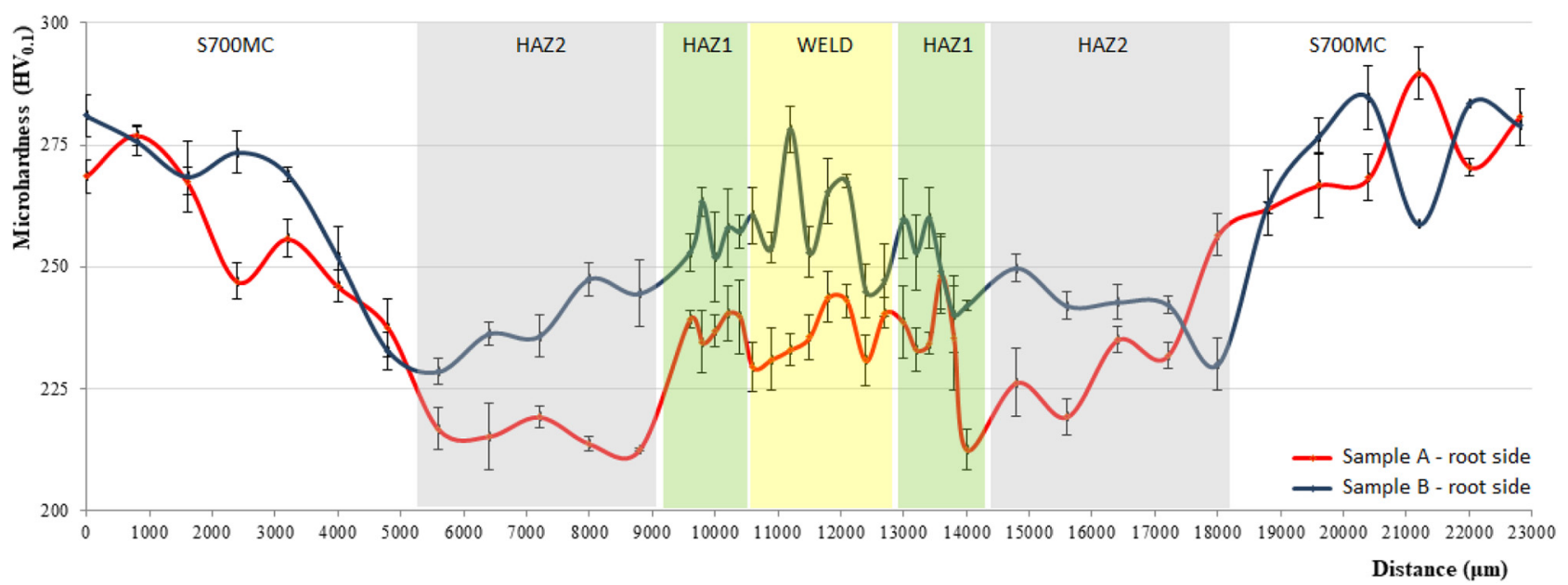

Fig. 18. Microhardness distribution in the hybrid plasma $+\mathrm{MAG}$ welded joints made of S700MC steel (2 mm from the bottom surface of the sheet at root side).

\section{References}

1. E.W. Reutzel, S.M. Kelly, R.P. Martukanitz, M.M. Bugarewicz, P. Michaleris, Laser-GMA Hybrid Welding: Process Monitoring and Thermal Modelling, in Proceedings of the 7th International Conference on Trends in Welding Research, Callaway Gardens Resort, Pine Mountain, Georgia, USA, edited by S.A. David et al. 2005, pp. 143-148

2. S. Katayama, Y. Naito, S. Uchiumi, M. Mizutani, Laser-arc hybrid welding, Solid State Phenom. 127 (2007) 295-300

3. J. Nowacki, A. Sajek, P. Matkowski, The influence of welding heat input on the microstructure of joints of S1100QL steel in one-pass welding, Arch. Civil Mech. Eng. 16 (2016) 777-783

4. J. Szulc, T. Chmielewski, Z. Pilat, Zrobotyzowane spawanie hybrydowe Plazma +MAG stali S700MC, Przegląd Spawalnictwa 88 (2016) 40-45

5. W. Wlosinski, T. Chmielewski, Plasma-hardfaced chromium protective coatings-effect of ceramic reinforcement on their wettability by glass, 3rd International Conference on Surface Engineering, Chengdu, China, October 10-13, 2002

6. Z. Pilat, J. Szulc, Concept of the model robotized cell for plasma-GMAW hybrid welding, Appl. Mech. Mater. 613 (2014) $43-52$

7. J. Górka, S. Stano, Microstructure and properties of hybrid laser arc welded joints (laser beam-mag) in thermo-mechanical control processed S700MC steel, Metals 8 (2018) 132

8. J. Górka, Weldability of thermomechanically treated steels having a high yield point, Arch. Metal. Mater. 60 (2015) 469-475

9. J. Górka, Study of structural changes in S700MC steel thermomechanically treated under the influence of simulated welding thermal cycles, Indian J. Eng. Mater. Sci. 22 (2015) 497-502

10. J. Górka, Welding thermal cycle-triggered precipitation processes in steel S700MC subjected to the thermomechanical control processing, Arch. Metal. Mater. 62 (2017) 321-326
11. J. Górka, D. Janicki, M. Fidali, W. Jamrozik, Thermographic assessment of the HAZ properties and structure of thermomechanically treated steel, Int. J. Thermophys. 38 (2017) 182

12. J. Górka, Microstructure and properties of the high-temperature (HAZ) of thermo-mechanically treated S700MC high-yieldstrength steel, Mater. Tehnol. 50 (2016) 617-621

13. T. Chmielewski, D. Golański, The role of welding in the remanufacturing process, Weld. Int. 29 (2015) 861-864

14. T. Sałacinski, M. Winiarski, T. Chmielewski, R. Świercz, Surface finishing using ceramic fiber brush tools, Proceedings of 26th International Conference on Metallurgy and Materials, METAL 2017, 1220-1226

15. T. Sałacinski, T. Chmielewski, M. Winiarski, R. Cacko, R. Swiercz, Roughness of metal surface after finishing using ceramic brush tools, Adv. Mater. Sci. 18 (2018) 20-27

16. A. Dolzhenkoa, Z. Yanushkevicha, S.A. Nikulinb, A. Belyakova, R. Kaibysheva, Impact toughness of an S700MC-type steel: Tempforming vs ausforming, Mater. Sci. Eng. A 723 (2018) 259-268

17. S.J. Spachinger, W. Ernst, N. Enzinger, Influence of Ti on the toughness of the FGHAZ and the CGHAZ of high-strength microalloyed S700MC steels, Weld World 61 (2017) 1117-1131

18. M. Opiela, Elaboration of thermomechanical treatment conditions of Ti-V and Ti-Nb-V microalloyed forging steels, Arch. Metal. Mater. 59 (2014) 1181-1188

19. D. Fydrych, J. Łabanowski, G. Rogalski, Weldability of high strength steels in wet welding conditions, Pol. Marit. Res. 20 (2013) 67-73

20. D. Fydrych, J. Łabanowski, G. Rogalski, J. Haras, J. Tomków, A. Świerczyńska, P. Jakóbczak, Ł. Kostro, Weldability of S500MC steel in underwater conditions, Adv. Mater. Sci. 14 (2014) 37-45

21. D. Fydrych, J. Łabanowski, J. Tomków, G. Rogalski, Cold cracking of underwater wet welded S355G10+N high strength steel, Adv. Mater. Sci. 15 (2015) 48-56 